\title{
Successful Management of Extended- Release Verapamil Intoxication: A Case Report
}

\section{Pınar Demir Gündoğmuş1, ๑ Ersin Doğanözü2}

${ }^{1}$ Kırıkkale Yüksek İhtisas Hospital, Clinic of Cardiology, Kırıkkale Turkey

229 Mayıs State Hospital, Clinic of Cardiology, Ankara, Turkey

\begin{abstract}
Treatment strategies for the management of verapamil intoxication are still unclear, although it can have fatal consequences. A 20-year-old female, who was treated regularly with extended-release verapamil $120 \mathrm{mg} / \mathrm{d}$ because of supraventricular tachycardia, took 15 tablets of extended-release verapamil $120 \mathrm{mg}(1800 \mathrm{mg})$. Her medical status deteriorated due to extended-release verapamil intoxication and she was successfully treated with cardiac pacemaker, fluid and electrolyte replacement and extracorporeal membrane oxygenation therapy (ECMO). Although supportive therapies are important in verapamil intoxication, development of atrioventricular block and fatal bradycardia is possible so pacemaker implantation on time and ECMO to accelerate decontamination can be life-saving as shown in the case.
\end{abstract}

Keywords: Extended-release, management, verapamil intoxication

\section{Introduction}

Verapamil is a potent calcium channel blocker agent that is frequently used in clinical practice. It reduces cardiac muscle contractility and atrioventricular (AV) nodal conduction by inhibiting calcium ion flow ${ }^{(1)}$. Excessive using of verapamil may cause severe hypotension, bradycardia, sinus arrest, cardiac conduction abnormalities, atrioventricular block, decreased cardiac output, confusion, convulsions, and hyperglycemia ${ }^{(1-4)}$. However, treatment strategies for the management of verapamil intoxication are still unclear, although it can have fatal consequences. Herein, we present a young female patient whose medical status deteriorated due to extended-release verapamil intoxication and who was

Address for Correspondence: Pınar Demir Gündoğmuş, Kırıkkale Yüksek İhtisas Hospital, Clinic of Cardiology, Kırıkkale Turkey e-mail: 1pinar.demir@gmail.com ORCID: orcid.org/0000-0001-8042-189X

Received: 10.10.2021 Accepted: 09.01.2022

Cite this article as: Demir Gündoğmuş P, Doğanözü E. Successful Management of Extended-Release Verapamil Intoxication: A Case Report. EJCM 2022;10(1):40-43.

DOI: $10.32596 /$ ejcm.galenos.2022.2021-10-050

${ }^{\circ}$ Copyright 2022 by Heart and Health Foundation of Turkey (TÜSAV) / E Journal of Cardiovascular Medicine published by Galenos Publishing House. 
successfully treated with cardiac pacemaker, fluid and electrolyte replacement and extracorporeal membrane oxygenation therapy (ECMO).

\section{Case Report}

A 20-year-old girl, who was treated regularly with extended-release verapamil $120 \mathrm{mg} / \mathrm{d}$ because of supraventricular tachycardia, took 15 tablets of extendedrelease verapamil $120 \mathrm{mg}$ (1800 mg) 20-30 minutes apart in nine hours in order to decrease palpitation. Four hours after taking the last drug, the patient presented to the emergency department with the complaints of chest pain and palpitation. On admission to the emergency department, blood pressure was 90/60 $\mathrm{mmHg}$, pulse was 103 beats/m and the electrocardiography (ECG) was in sinus rhythm and 96 beats/m and echocardiography revealed normal myocardial function. One hour later, the patient had weakness, chest and epigastric pain and the blood pressure was $60 / 40 \mathrm{mmHg}$ and fluid and volume replacement was started. The patient was hospitalized in the coronary intensive care unit and then immediately started intra-arterial blood pressure monitoring. Transcutaneous pacemaker pads were placed to the patient and prepared for pacing as needed. It was started intestinal irrigation with polyethylene glycol solution. At the second hour, respiratory rate was $25 / \mathrm{min}$, heart rate was 107 beats/min and body temperature was 35.5 degrees. The patient was hypotensive despite the volume replacement so dopamine and noradrenalin infusion was administered. $\mathrm{NaHCO}_{3}$, electrolyte and $\mathrm{Ca}$ gluconate (10\%) replacement was started. At the third hour, blood pressure was 78/45 $\mathrm{mmHg}$ with positive inotropic and vasopressor support. $\mathrm{NaHCO}_{3}$ and electrolyte replacement was continued and the patient who developed first degree AV block underwent transient pace implantation via right femoral vein because of hemodynamic instability despite volume and positive inotropic support (Figure 1A). When the heart rate was about $90 / \mathrm{pm}$ with the pacemaker, adequate tissue perfusion achieved successfully, so the pacemaker was kept working (patient's ECG with pacemaker is Figure 1B). And then, cyanosis, cool extremities and altered mental status were observed so the patient was intubated under sedation because of pulmonary edema (Figure 2). At the sixth hour after taking verapamil, blood gas parameters under mechanical ventilation support were as follows: $\mathrm{pH}: 7.2, \mathrm{HCO}_{3}: 16.6 \mathrm{mmol} / \mathrm{L}$. And base deficit was increased. Her blood pressure was 90/50 $\mathrm{mmHg}$. At the eighth hour, positive inotropic agent, pacemaker stimulation and mechanical ventilatory support were continued. Her blood pressure was $85 / 45 \mathrm{mmHg}$. Blood gas parameters under mechanical ventilation support were pH: 7.07, $\mathrm{pCO}_{2}: 42 \mathrm{mmHg}$ and $\mathrm{HCO}_{3}: 8.4 \mathrm{mmol} / \mathrm{L}$. The total urine output was $100 \mathrm{cc}$ since the admission. The patient deteriorated because of progression of acidosis, and ECMO was decided to be applied to the patient. After one hour, it was observed as $\mathrm{pH}$ : 7.20, $\mathrm{PCO}_{2}: 44.1$ $\mathrm{mmHg}$ and $\mathrm{HCO}_{3}: 16.6 \mathrm{mmol} / \mathrm{L}$. Blood pressure control and adequate urine output were achieved and the patient's blood gas parameters returned to normal. ECMO was terminated after 36 hours and there was no need for pacing (ECG of the patient after the termination of pacemaker application is in Figure 1C). The patient was discharged on the tenth day.

\section{Discussion}

Verapamil intoxication is a well-known fatal medical condition and the main treatment principle is to take supportive measures ${ }^{(2)}$. Extended-release verapamil peaks 6-8 hours after ingestion, but overdose symptoms begin within one to two hours. Poisoning with an extendedrelease formulation is generally more severe due to sustained release and increase in plasma level over a long period of time ${ }^{(3)}$. In our patient, poisoning occurred with $1800 \mathrm{mg}$ extended- release verapamil. Cardiogenic shock and noncardiogenic pulmonary edema developed. The successful management of verapamil intoxication in our patient prevented undesirable outcomes.

Gastric lavage may be recommended in early admission, but the main treatment principle of verapamil intoxication is to take supportive measures ${ }^{(5)}$. In our case, although the drug was taken intermittently, gastrointestinal 

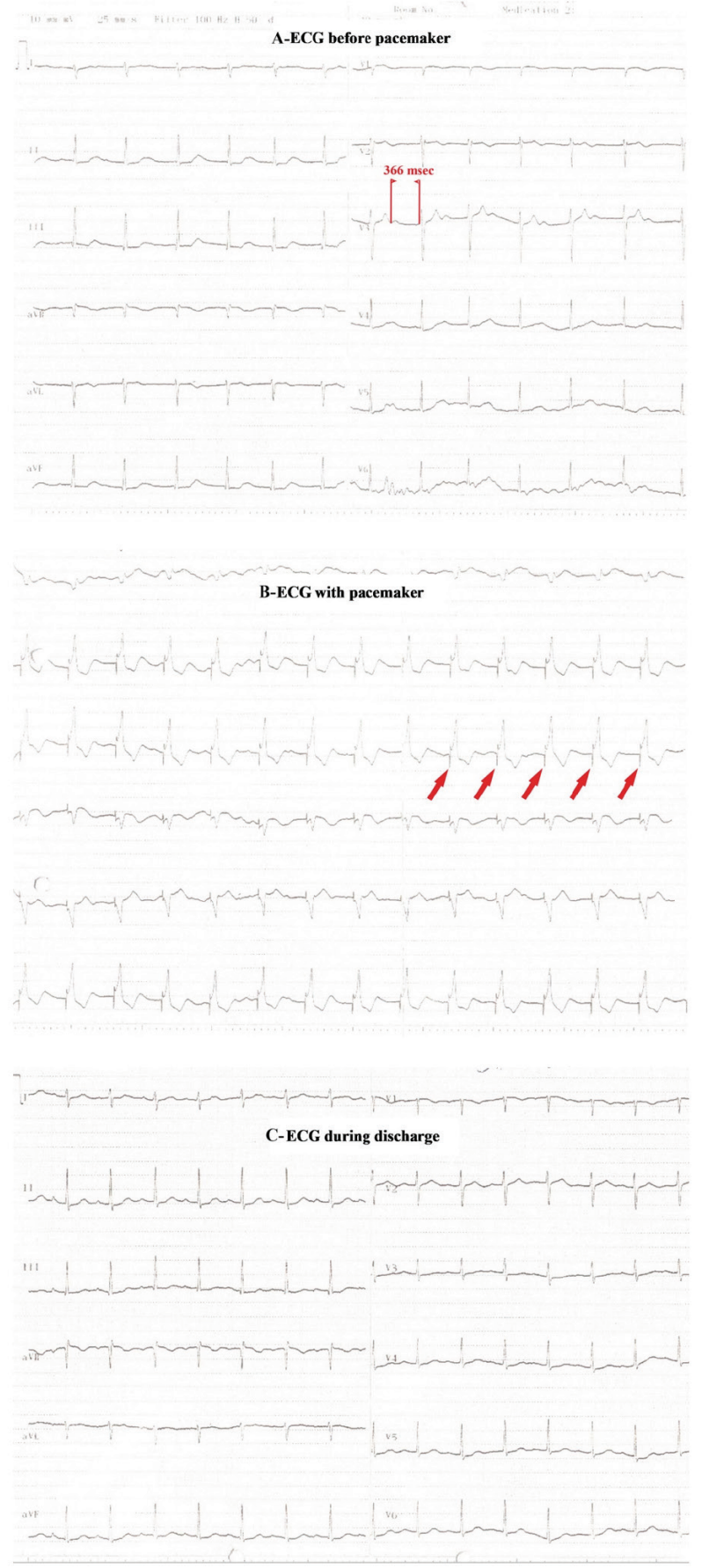

Figure 1. Three different electrocardiographs of the patient's treatment process. A) ECG of the patient before pacemaker application (The red marks show the distance between PR; $366 \mathrm{msec}$, first degree AV block). B) ECG of the patient after pacemaker application (The red marks indicate pacemaker spikes.). C) ECG of the patient after discharge

ECG: Electrocardiography, AV: Atrioventricular irrigation was performed with polyethylene glycol solution. Since we were unable to detect drug levels of plasma, we could not know how effective this intervention was. Another treatment principle is the administration of vasopressor agents, glucagon infusion, hyperinsulinemiceuglycemia treatment and intravenous lipid emulsions to provide circulatory support and decontamination ${ }^{(6)}$. In our patient, fluid and volume replacement, dopamine, noradrenalin and $\mathrm{Ca}$ gluconate treatment and $\mathrm{NaHCO}_{3}$ and electrolyte replacement were performed. In the patient, noncardiogenic pulmonary edema developed as reported in the literature ${ }^{(4)}$.

There was an interesting condition about our patient. The patient underwent transvenous transient pacemaker implantation because of the development of first AV block because we saw that the patient deteriorated when prolonged AV conduction occurred. We thought that this was due to atrial systole, which is too early in diastole, and caused an ineffective or decreased contribution of atrial systole to cardiac output. Maybe this is not important in hemodynamically stabile patients but our patient had an inadequate circulation due to vasodilatation and hypotension so she could not tolerate such as defect about cardiac output $^{(7)}$.

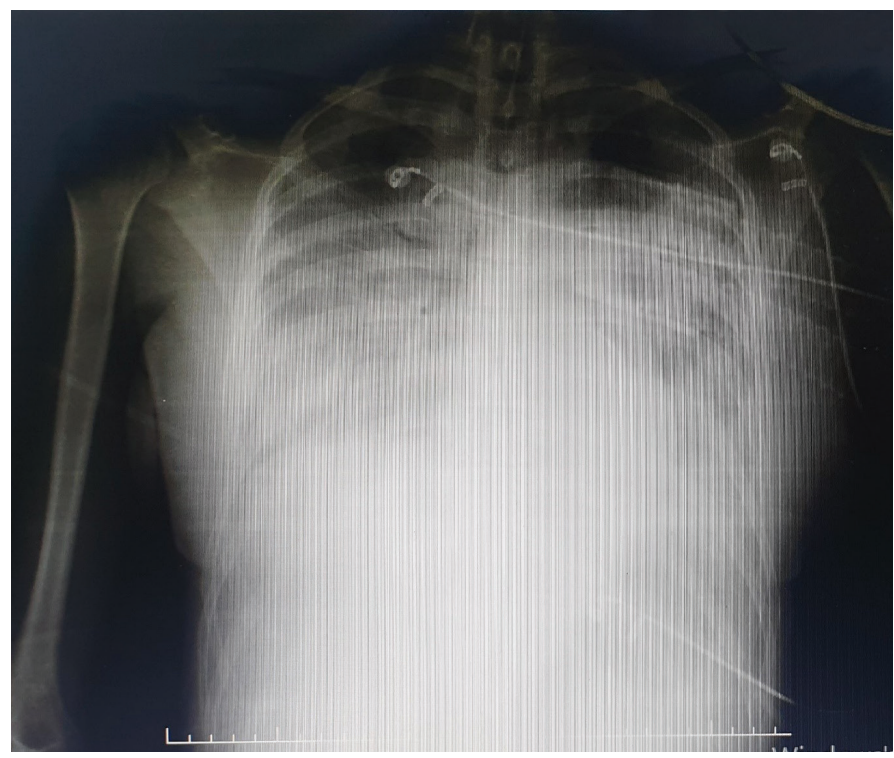

Figure 2. Chest X-ray showing that the patient has pulmonary edema 
In case of resistant intoxication despite supportive treatment; the main treatment should be decontamination of verapamil. For this purpose; hemofiltration, cardiopulmonary bypass, therapeutic plasma exchange and continuous hemofiltration may be effective ${ }^{(8,9)}$. There are also reports stating that ECMO may be effective ${ }^{(8)}$.

In conclusion, verapamil intoxication is a well-known fatal medical condition. Although supportive therapies are important, development of AV block and fatal bradycardia is possible so pacemaker implantation on time and ECMO to accelerate decontamination can be life-saving as shown in the case. We believe in that planning of pacemaker and ECMO will increase the chances of successful treatment and save the patient from the fatal consequences.

\section{Ethics}

Informed Consent: The patient's consent was obtained for the article.

Peer-review: Externally peer-reviewed.

\section{Authorship Contributions}

Concept: P.D.G., E.D., Design: P.D.G., E.D., Data Collection and/or Processing: P.D.G., E.D., Literature Search: P.D.G., E.D., Writing: P.D.G., E.D., Critical Review: P.D.G., E.D.

Conflict of Interest: No conflict of interest was declared by the author.
Financial Disclosure: The authors declared that this study received no financial support.

\section{References}

1. Moser M. Current recommendations for the treatment of hypertension: are they still valid? J Hypertens Suppl 2002;20:S3-10.

2. Mandigers L, Bollen PD, Bijlstra PJ, Brands E. Severe verapamil intoxication despite correct use of low-dose verapamil. Drug Metab Pers Ther 2016;31:55-8.

3. French D, Armenian P, Ruan W, et al. Serum verapamil concentrations before and after Intralipid ${ }^{\circledR}$ therapy during treatment of an overdose. Clin Toxicol (Phila) 2011;49:340-4.

4. Sami Karti S, Ulusoy H, Yandi M, et al. Non-cardiogenic pulmonary oedema in the course of verapamil intoxication. Emerg Med J 2002;19:4589.

5. Buckley N, Dawson AH, Howarth D, Whyte IM. Slow-release verapamil poisoning. Use of polyethylene glycol whole-bowel lavage and high-dose calcium. Med J Aust 1993;158:202-4.

6. Liang CW, Diamond SJ, Hagg DS. Lipid rescue of massive verapamil overdose: a case report. J Med Case Rep 2011;5:399.

7. Barold SS, Ilercil A, Leonelli F, Herweg B. First-degree atrioventricular block. Clinical manifestations, indications for pacing, pacemaker management \& consequences during cardiac resynchronization. J Interv Card Electrophysiol 2006;17:139-52.

8. Kolcz J, Pietrzyk J, Januszewska K, Procelewska M, Mroczek T, Malec E. Extracorporeal life support in severe propranolol and verapamil intoxication. J Intensive Care Med 2007;22:381-5.

9. Pfaender M, Casetti PG, Azzolini M, Baldi ML, Valli A. Successful treatment of a massive atenolol and nifedipine overdose with CVVHDF. Minerva Anestesiol 2008;74:97-100. 